\title{
Implementation of Spectrum Sensing based OFDM Transceiver using Xilinx System Generator
}

\author{
Areej Munadel Kadhum ${ }^{1}$, Ekhlas Kadhum Hamza ${ }^{2}$ \\ ${ }^{1,2}$ Control \& System Engineering Dept, University of Technology, Baghdad, Iraq. \\ 'areejmunadel5@gmail.com, ${ }^{2} 100374 @$ uotechnology.edu.iq
}

\begin{abstract}
- with the introduction of new standards at a fast pace, wireless communication is experiencing great development and growth, thereby raising the level of demand for radio spectrum. The spectrum, however, is a limited resource and cannot be subdivided indefinitely to satisfy any use. As a result, spectrum scarcity arises. This scarcity represents the main problem that faces the future of wireless networks. This scarcity is due to the inefficient fixed spectrum allocation technique. The Dynamic Spectrum Access (DSA) is a successful solution to reduce the spectrum scarcity that wireless communications currently face. DSA allows users without a spectrum license known as Secondary Users (SUs) to temporarily use the unused licensed spectrum. This work focuses on analysis, and design of the Cognitive Radio $(C R)$ system forOrthogonal Frequency Division Multiplexing modulation. The OFDM transceiver system has been implemented in the first stage using the Quadrature Phase Shift Keying (QPSK) modulation technique by Xilinx System Generator Inter-Symbol InterferenceSimulink (XSG) based on MATLAB. The second stage of the proposed system is to design energy detection of the OFDM transceiver. This system was analyzed under the Adaptive White Gaussian Noise (AWGN) channel based XSG. In this work, the energy detector is also designed using the XSG ISE14.1 Simulink and obtained all the signals successfully.
\end{abstract}

Index Terms - CR, Spectrum Sensing, OFDM, QPSK, ED, AWGN.

\section{INTRODUCTION}

Wireless networks are increasing at an exponential pace, requiring a greater and larger radio spectrum for cellular communications. Cognitive Radio (CR) allows users to use frequencies that conventional radios cannot. Additionally, it allows for more efficient use of the spectrum. A cognitive radio system, which can learn from the external radio environment and adjust its contact settings to optimize its effectiveness, can maximize spectrum utilization. As the secondary user is required to return the occupied spectrum whenever the primary user appears, it is therefore important for the secondary user to be able to periodically sense the availability of the licensed spectrum.

Since the Orthogonal Frequency Division Multiplexingsignal is split into several orthogonal subcarriers, OFDM is now a relatively new transmission technique that enables the signal to be transmitted on some of the sub-carriers. In cognitive radio, "OFDM" has become the most common method that use[1]. Applying the OFDM to cognitive radio would bring advantages in shaping the spectrum to make it easier for the secondary user to access the available spectrum and increase the performance of the spectrum use of the entire system[2]. OFDM is a multiple carrier, multiple tone, and Fourier transform modulation scheme. As the name suggests, the basic concept of OFDM is that you send all of the data over several different carriers, each of which is modulated at a low rate, the carriers are orthogonal to each other and the data are spaced equally from each other by choosing the necessary frequency spacing between them[3]. A process, which known as Frequency Division multiplexing, divides the spectrum available into a number of sub-bands, which are then transmitted in parallel by multiple channels (carriers). It combines a large number of low data rate carriers to create a composite high data rate communication system $[4,5]$. In this paper, look at the spectrum efficiency and energy efficiency that OFDM-based Cognitive Radio (CR) networks can offer to wireless systems 
spectrum efficiency. The remaining part of paper will be structured in the following way. Section II discusses the cognitive radio cycles, Section III deals with the OFDM transceiver, using Xilinx System Generator (XSG) based energy, performs energy detection using a simple mask detection. Thee results will be mentioned in the next portion. Finally, Section V includrs the conclusion that is inferred in this work.

\section{COGNITIVE RADIO CYCLE}

The main stages of the cognitive radio cycle are shown in Fig. 1:

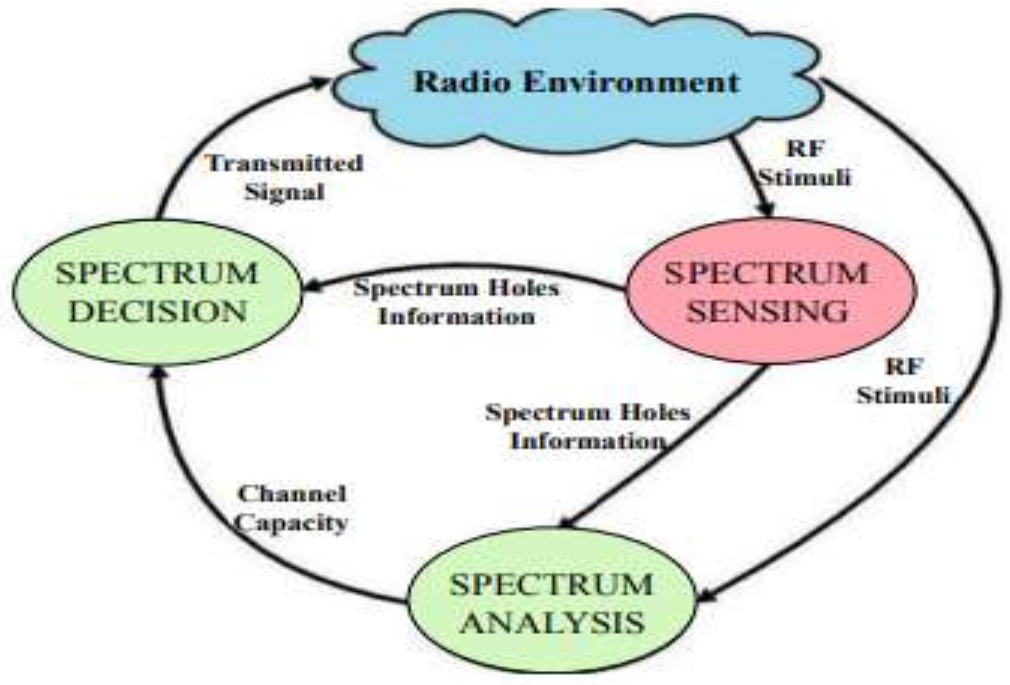

Fig. 1. Cognitive Radio Cycle[6]

1. Spectrum sensing: Cognitive radio senses the spectrum available, collects its information, and then senses the holes in the spectrum. Spectrum sensing is also able to conduct the correct observations of the spectrum holes to support the analysis process of the spectrum category[7]. If the CR continues to camp on the touch spectrum, the occupied narrow band will be monitored to determine whether or not the original licensed user is reappearing.

2. Spectrum analysis: the CR calculates the properties of these bands which have been observed in spectrum sensing[6].

3. Spectrum decision: Cognitive radio decides the information rate, the transmitting hub, and the bandwidth of the transmitter. The required spectrum band is then selected in accordance with the spectrum characteristics and customer requirements. If spectrum holes are found, the next major step is to select the current best spectrum suited to the particular Quality of Service (QoS) requirements of the user[8].

\section{SYSTEM MODEL}

The manner of OFDM and Energy detection spectrum sensing is described in Fig. 2. 


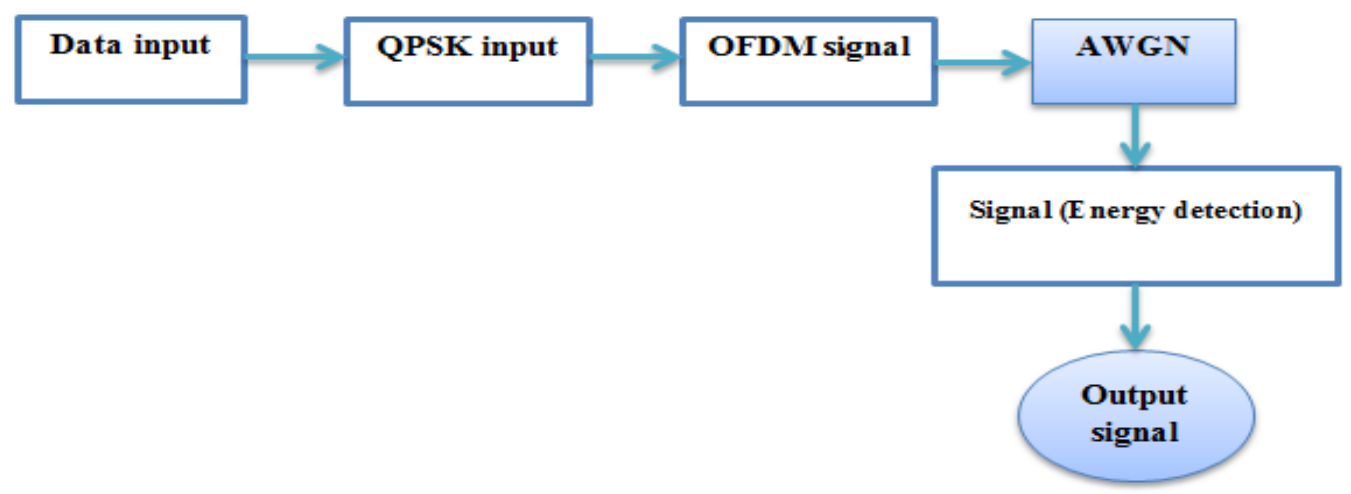

\section{DESIGN OFDM TRANSMITTER}

Fig. 2. PROPOSED-SYSTEM CONFIGURATION

Fig. 3 explains the block diagram of the OFDM transmitter that is simulated and implemented using MATLAB/ System Generator Simulink. The OFDM transmitter is a combination of these distinct parts i.e., the Random Integer Generator, QPSK Subsystem for the data input, zero padding (the I and Q channels.), and the Fast Fourier Transform.

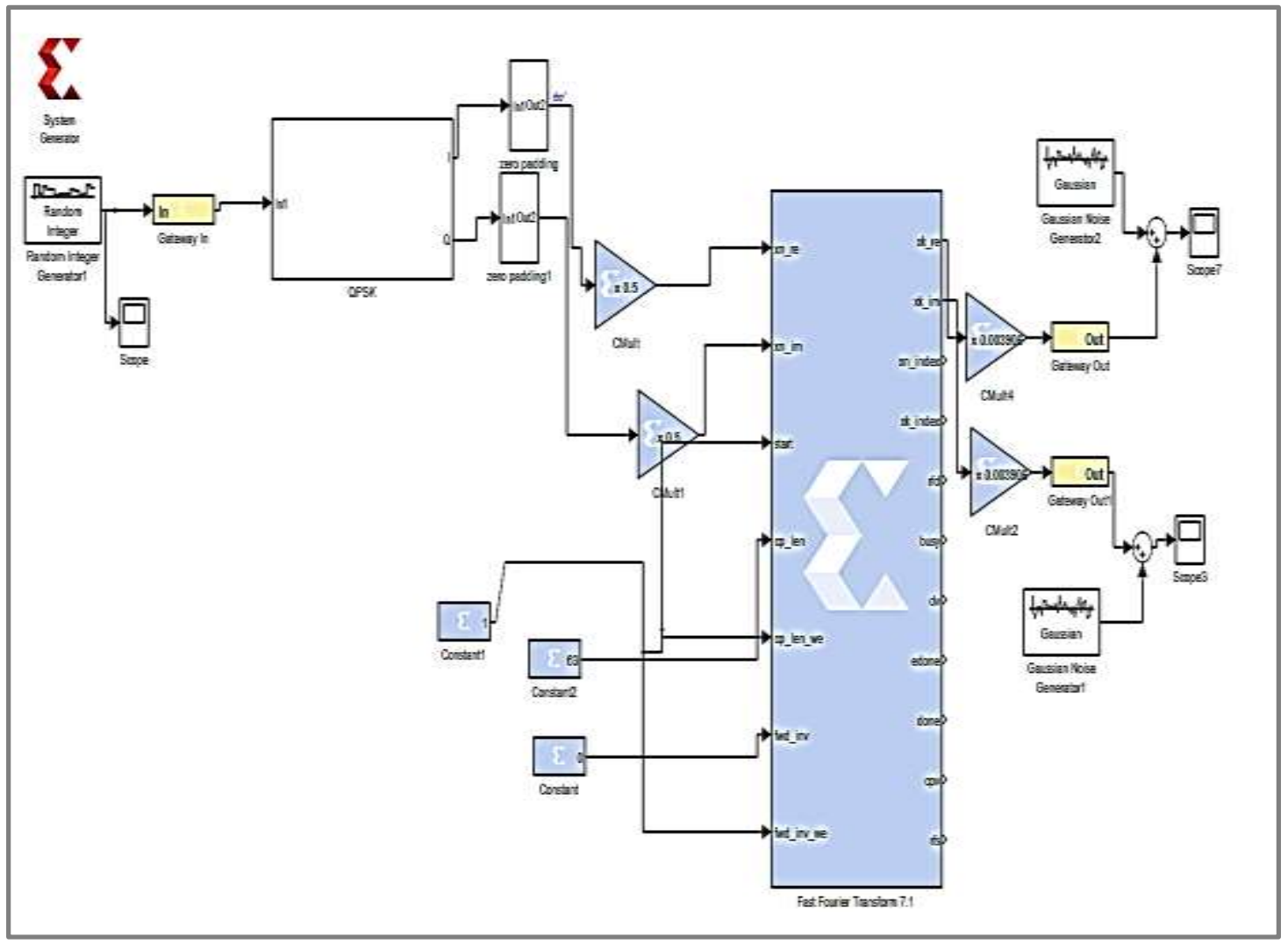

FIG . 3. OFDM TRANSMITTER BASED CR USING XILINX

Random bit generator block generates the data for all systems that will be run. In this step, random bits are generated by sampling time 1 and initial seed 37. Gateway In block used to translate into the fixed-point form of Device Generator.

The data will enter the Quadrature Phase Shift Keying after producing an input data sequence. QPSK has been implemented with Serial to parallel (unsigned, number of bits 2). The Xilinx ROM block stores four words corresponding to "00," "01", "10" and "11" and two mappers (Mapper_I, Mapper_Q) with depth 4 and initial value vector [ $\left[\begin{array}{llll}1 & 1 & -1 & -1\end{array}\right]$. Fig 4 and Fig. 5 represent the subsystem of QPSK, and zero padding[9]. 


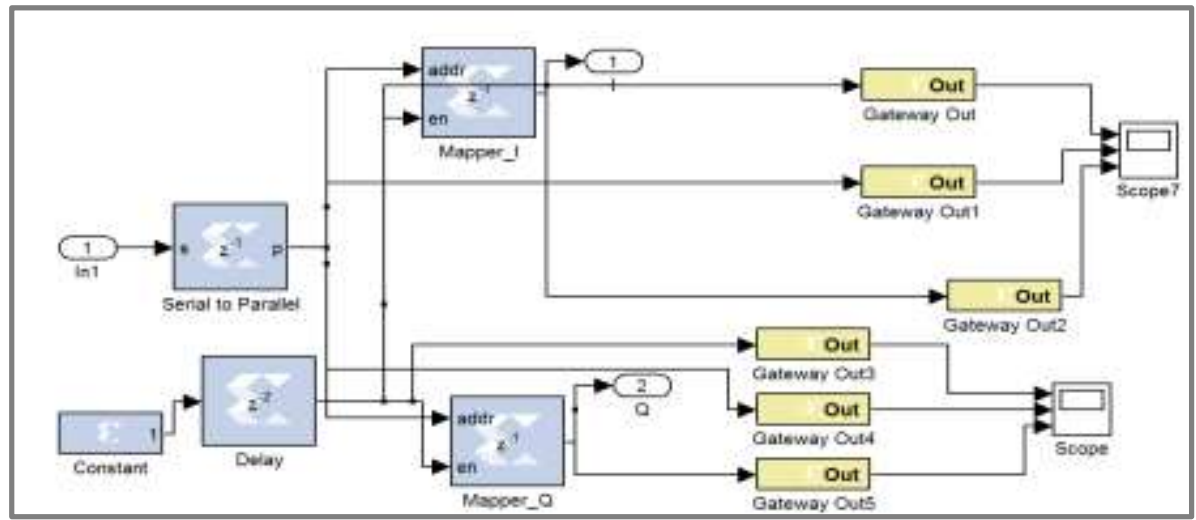

FIG.4. QPSK SUBSYSTEM DESIGN

After designning QPSK, the zero-padding process is performed on the transmitter side before the FFT transformation. To obtain a finer sampling of the Fourier transform, a zero-padding is applied to $\mathrm{f}$ when calculating its Discrete Fourier Transform (DFT). Fig 5 below shows the sub system block of zero padding.

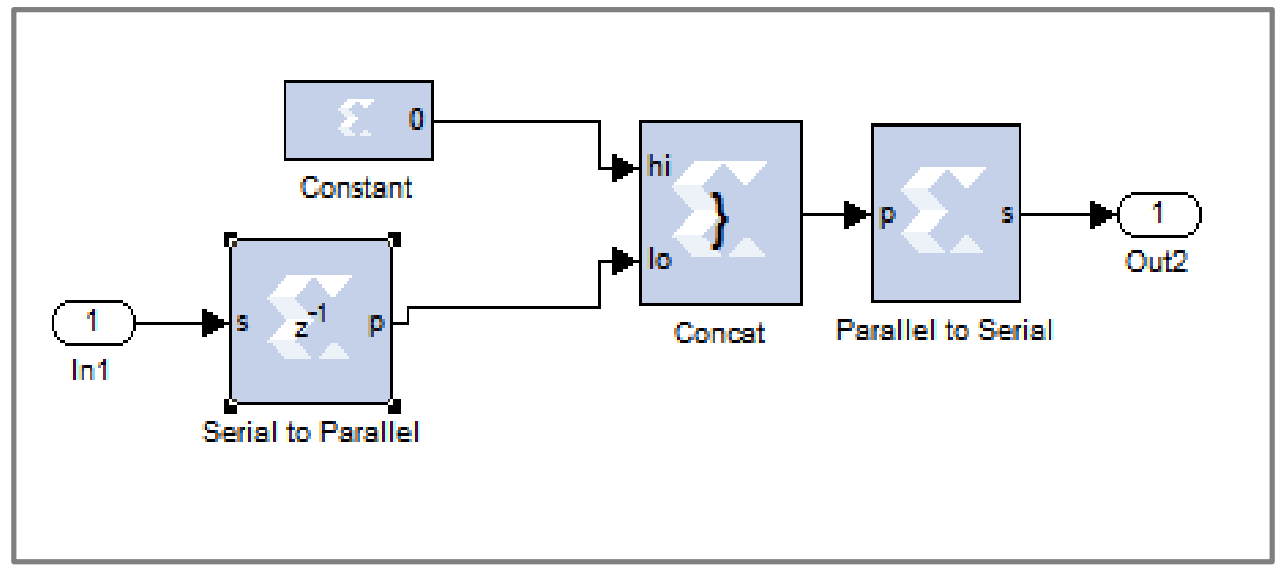

Fig.5. ZeRo PADDING SUbSYSTEM DESIGN.

The Serial to parallel takes a set of input data of any size and produces a single output of the multiple of that size specified. The Xilinx constant block allows us to send in a constant that can be taken as a fixed-point value, a Boolean value, or a digital signal processor48order.

In this block, the gain is applied with a gain operator, with an output that is equal to the product of its input value by a constant. This value may be an expression using parentheses that evaluates to a constant. The constant value equals to 0.5 was used as input to the FFT algorithm, and the constant value of 0.003906 was the output of the FFT algorithm. The parallel to the serial block takes an input word, splits that word into $\mathrm{N}$ time-multiplexed output words where $\mathrm{N}$ is the ratio of the number of input bits to the number of bits of that single output word. The output order determines if the least significant bit is the first one or whether the most significant bit is the first one.

The Xilinx FFT is a computationally powerful sample size Discrete Fourier Transform (DFT) that computes algorithm with a positive integer power of 2 . The block interface used to modulate and demodulate the OFDM signalmis is shown in Fig 6.

bits are input to the number of bits of that single output word. The output order determines if the least significant bit is the first one or whether the most significant bit is the first one.

The Xilinx FFT is computing algorithm with a positive integer power of 2 . The block interface used to modulate and demodulate the OFDM signalmis is shown in Fig.6. 


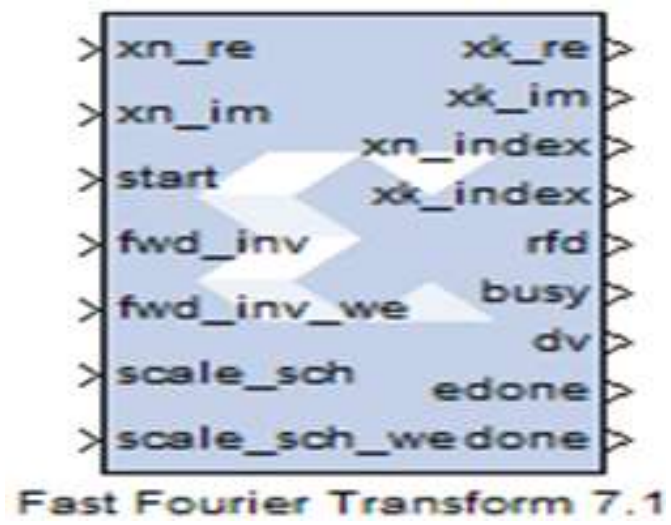

Fig.6. XILINX FFT BLOCK.

TABLE 1. FEATURES USED IN THE PROPOSED OFDM TRANSCEIVER OF ENERGY DETECTION MODEL.

\begin{tabular}{|ll|}
\hline \multicolumn{1}{|c|}{ Feature } & \multicolumn{1}{c|}{ Value } \\
\hline Channel & AWGN channel \\
\hline Number of iteration & 1000 \\
\hline OFDM Length & 64 \\
\hline Modulation technique & QPSK modulation \\
\hline Threshold & Threshold determined using probability false alarm \\
\hline
\end{tabular}

In this work, AWGN was used to model the communication channel. This block incorporates real Gaussian noise when the input signal is real and generates a real output signal.

\section{Design OFDM Receiver based Energy Detection}

Finally, The OFDM Receiver dependent energy detection is discussed in this section. The energy detector's process flow is the signal received from FFT through AWGN, and then squared those values over the observation period and average. The detector output is then compared to a pre-defined threshold value to determine whether the primary user is present or not. The overall system implementation structure, which uses the Xilinx system generator and includes the transmitter and receiver, is shown in Fig. 7. 


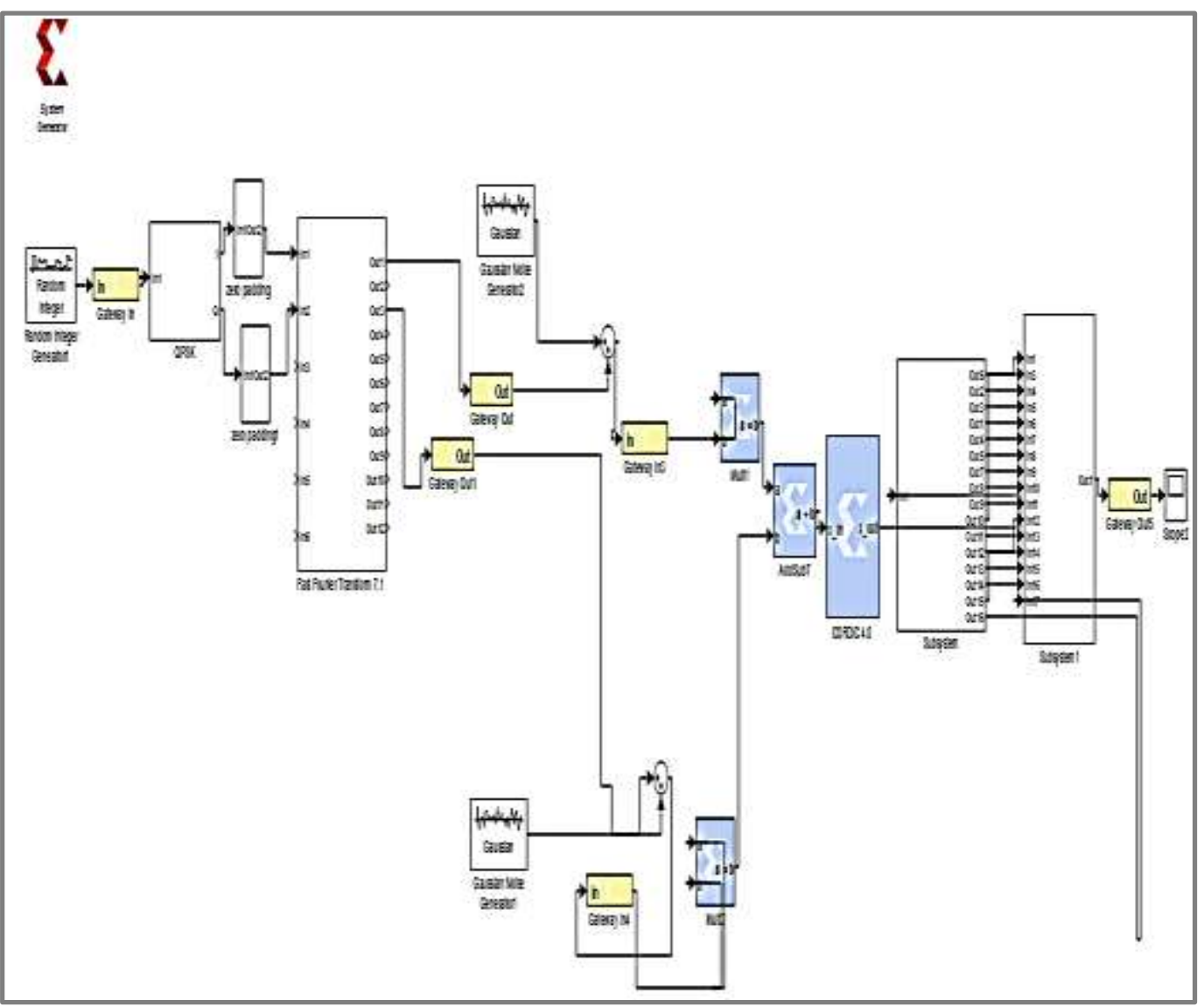

FIG.7. DESIGN OF XSG OFDM TRANSCEIVER BASED CR.

The sub- system design of the energy detection is further shown separately in Fig. 8 and. 9. it is implemented using Xilinx blocks, Register, Delay, constant, Linear-Feedback Shift Register, Mult, and Add. Fig, 8 shows the sub- system of serial to parallel, which is used to convert the data received from the OFDM transmitter to parallel form.Then the output signal is taken after 16 clock puls.

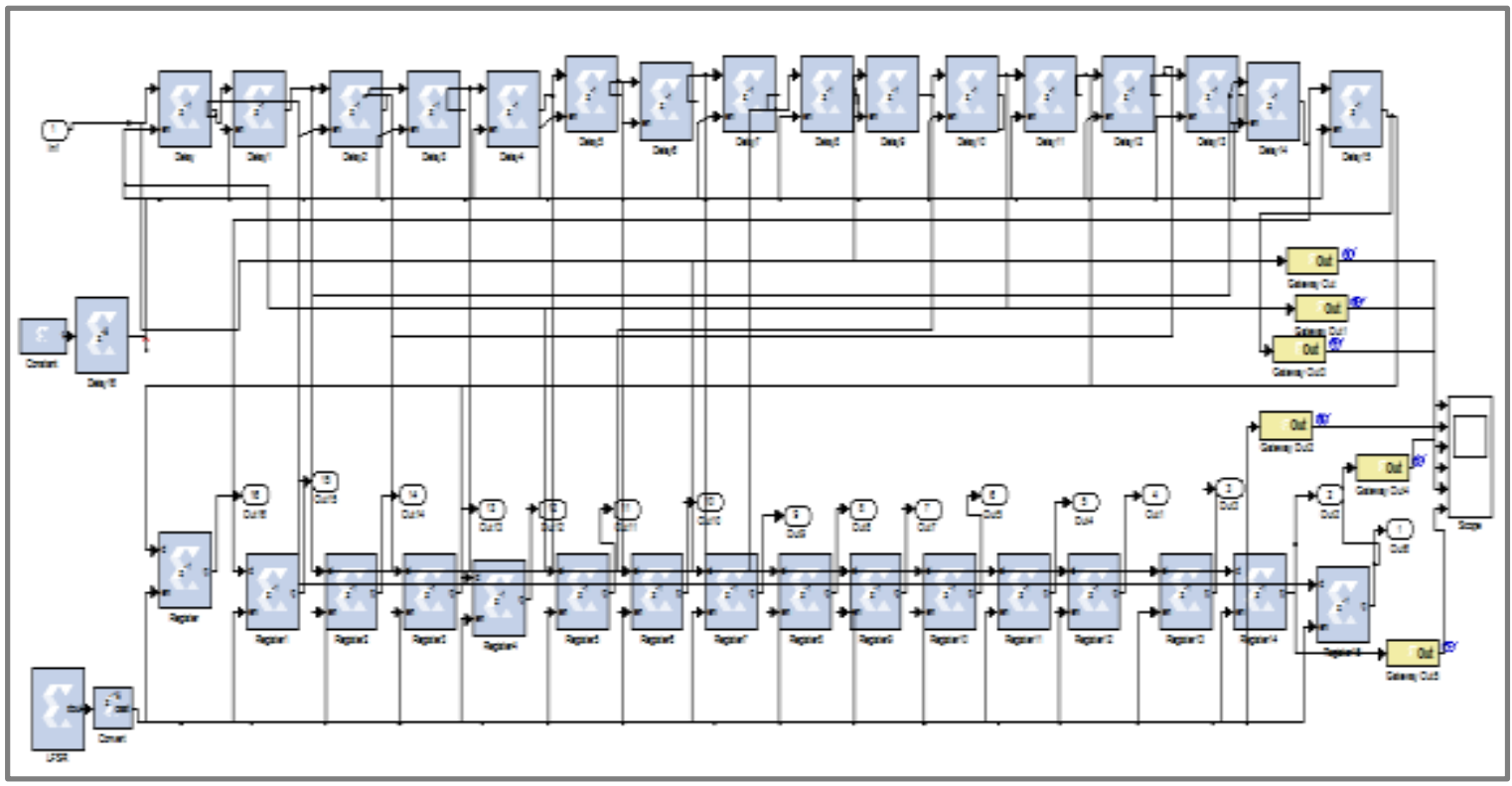

Fig.8. XSG BLOCK OF SERIAL TO PARALLEL[10]. 


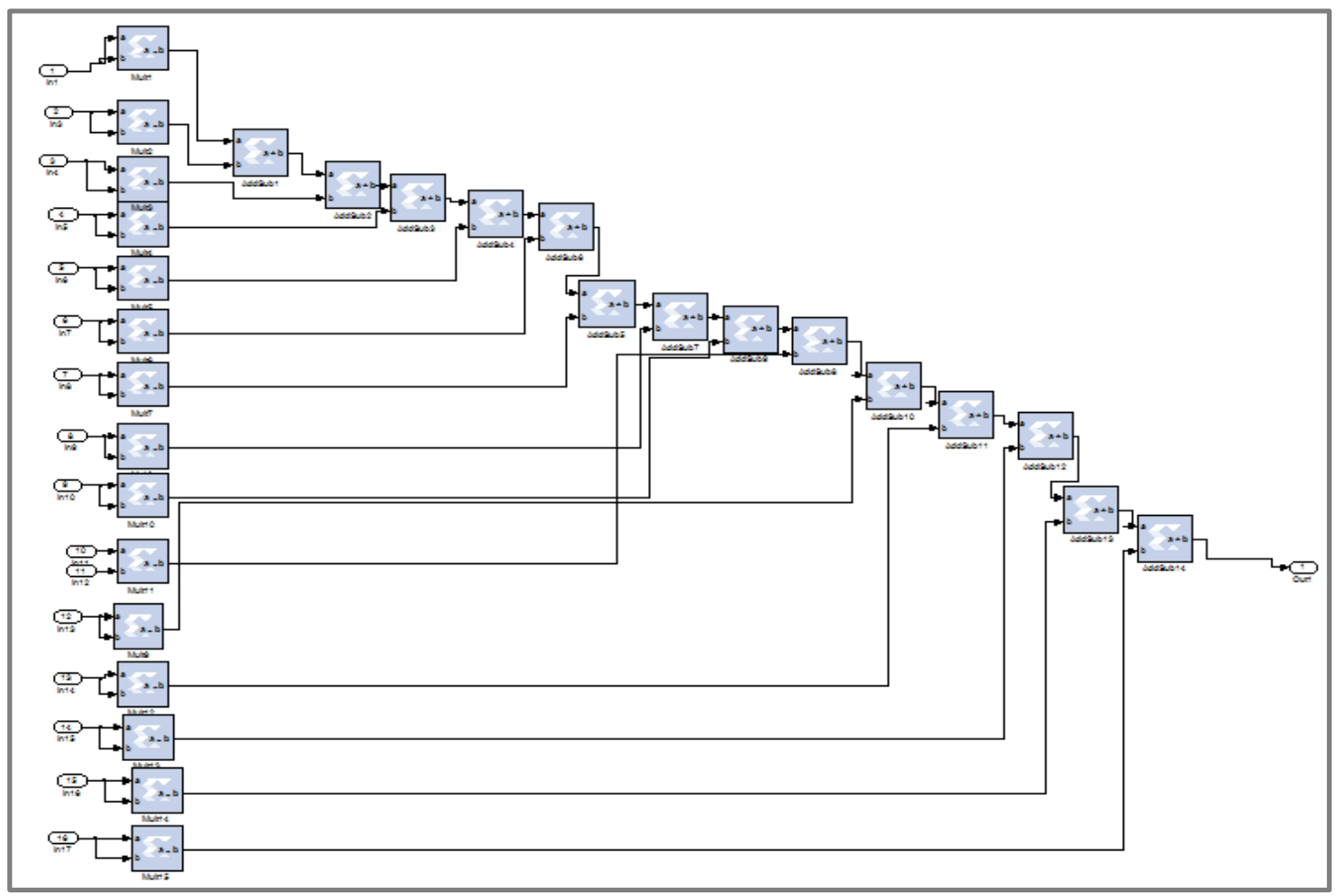

FIG.9.XSG BLOCK DIAGRAM OF SUB SYSTEM ENERGY DETECTION.

\section{XSG SIMULATION RESULT}

By using the MATLAB/Simulink program, the resulting waveforms, which describe the outputs of and variable in the proposed system implemented using XSG, are plotted. The details of the waveform output of the random integer generator are shown in Fig. 10.

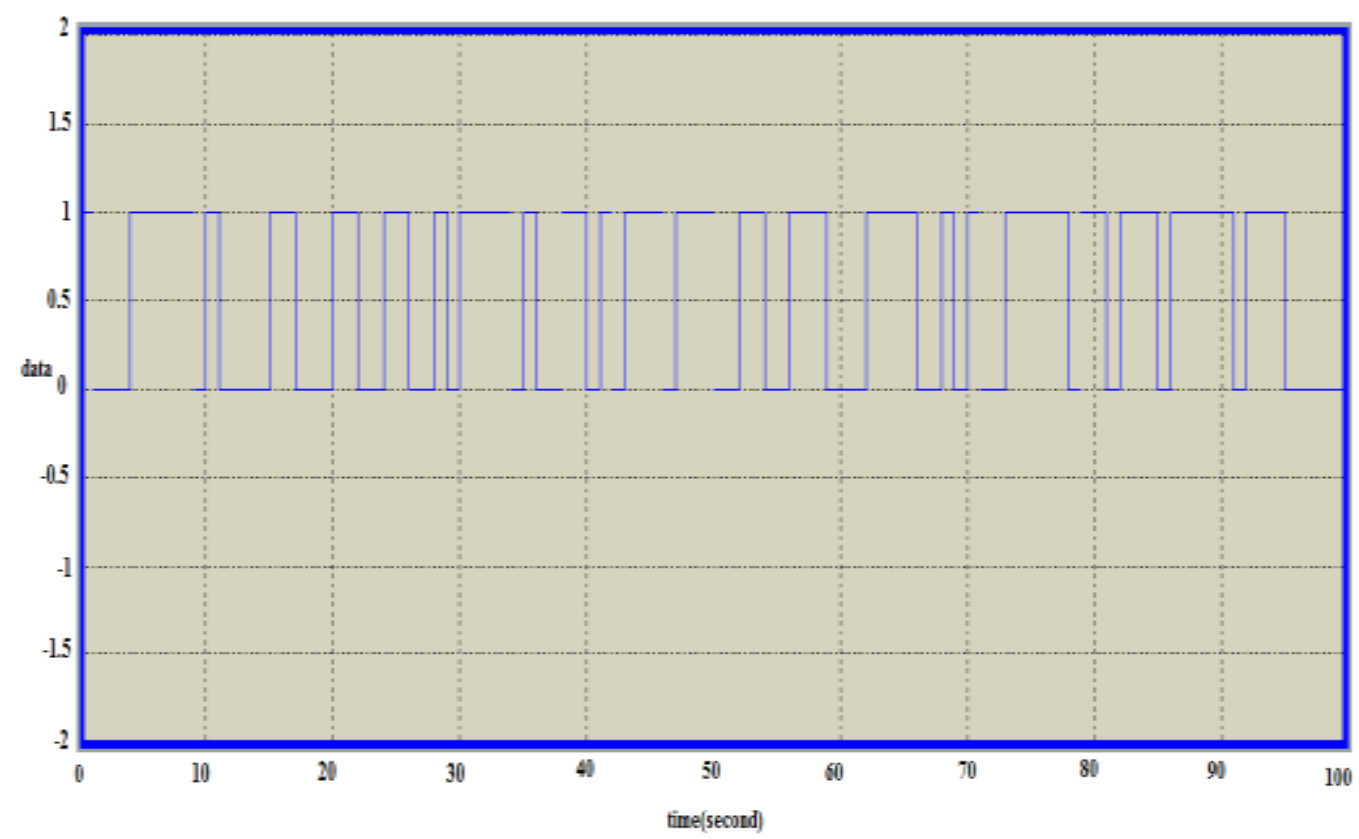

Fig.10. DATA INPUT STREAM. 
Fig. 11 and 12 Show the positions of scope with three inputs, respectively. The first is the serial to parallel, the second is delay with latency $=2$, and the third is Mapper_ I, and Mapper_Q.

$\mathbf{a}$

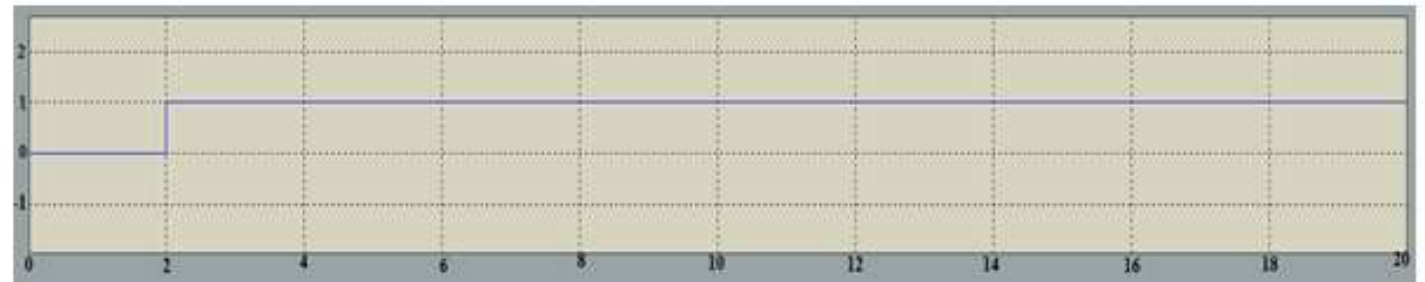

b

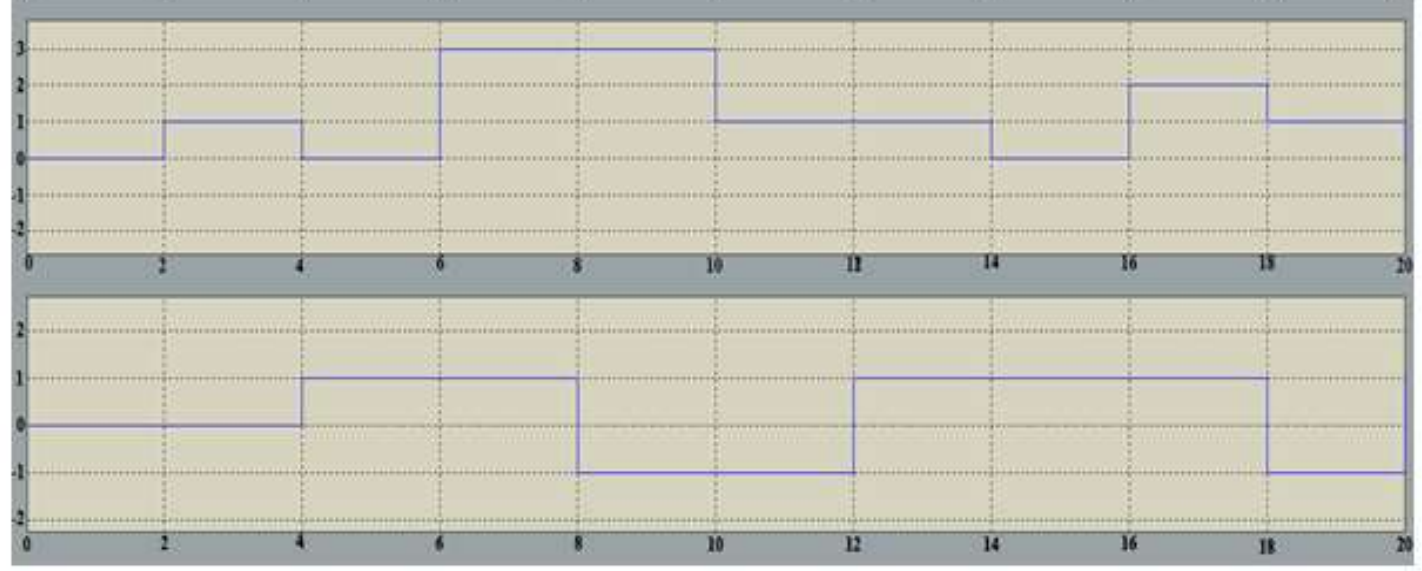

Simulink time (ns)

Fig.11. ( A) Delay With LATENCy =2 (B) Serial to PARALlel (C) IN- PHASE.

a

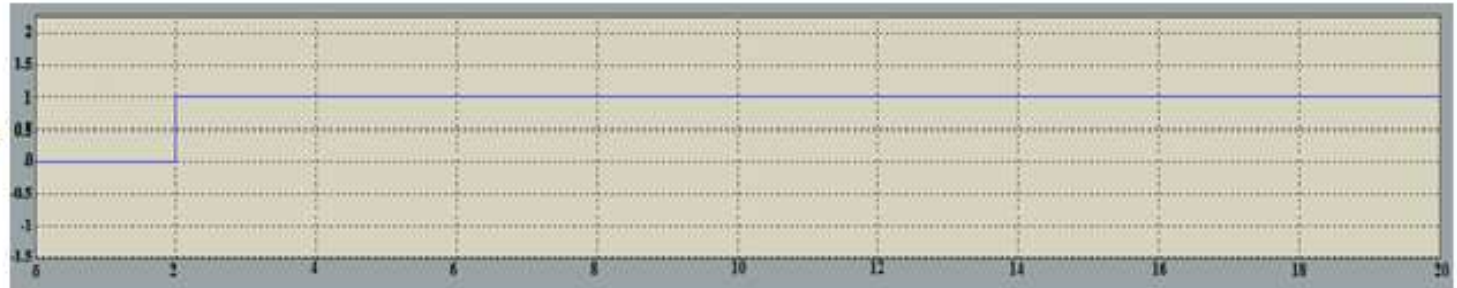

b

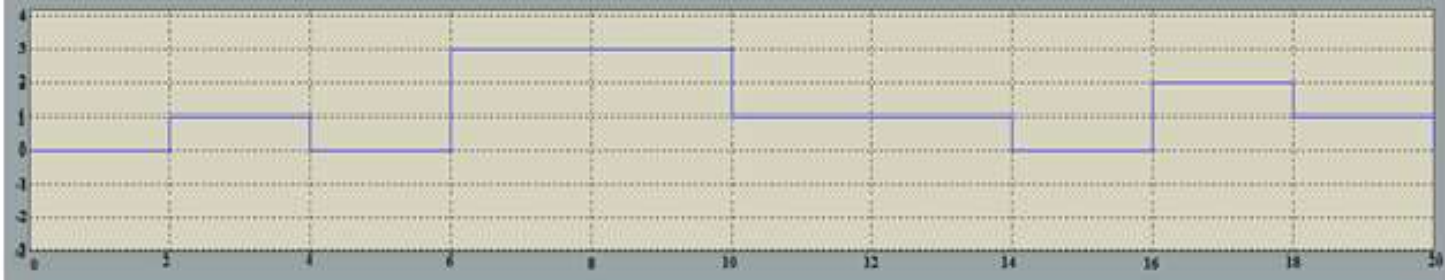

c

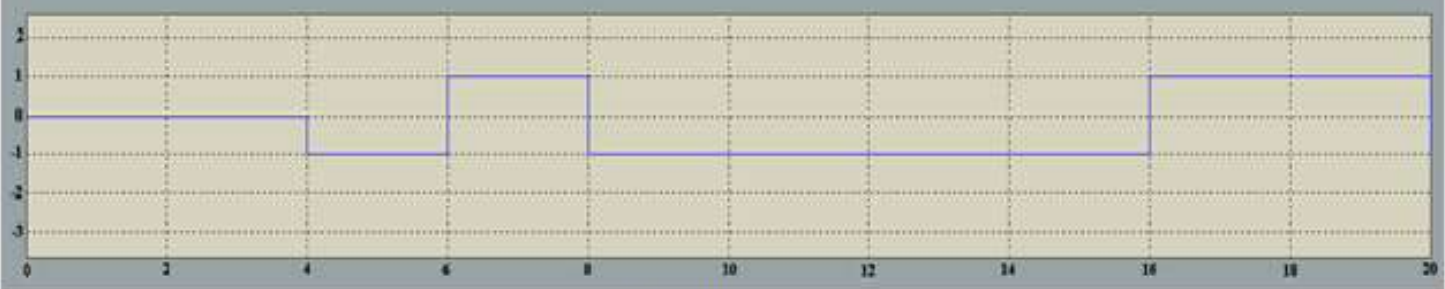

Simulink time (ns)

Fig.12. (A) DElay With LATENCy =2 (B) SERIAl to PARALlEl (C) QuAdRATURE- PHASE.

Fig. 13 displays OFDM's output waveform XSG simulation waveforms. 


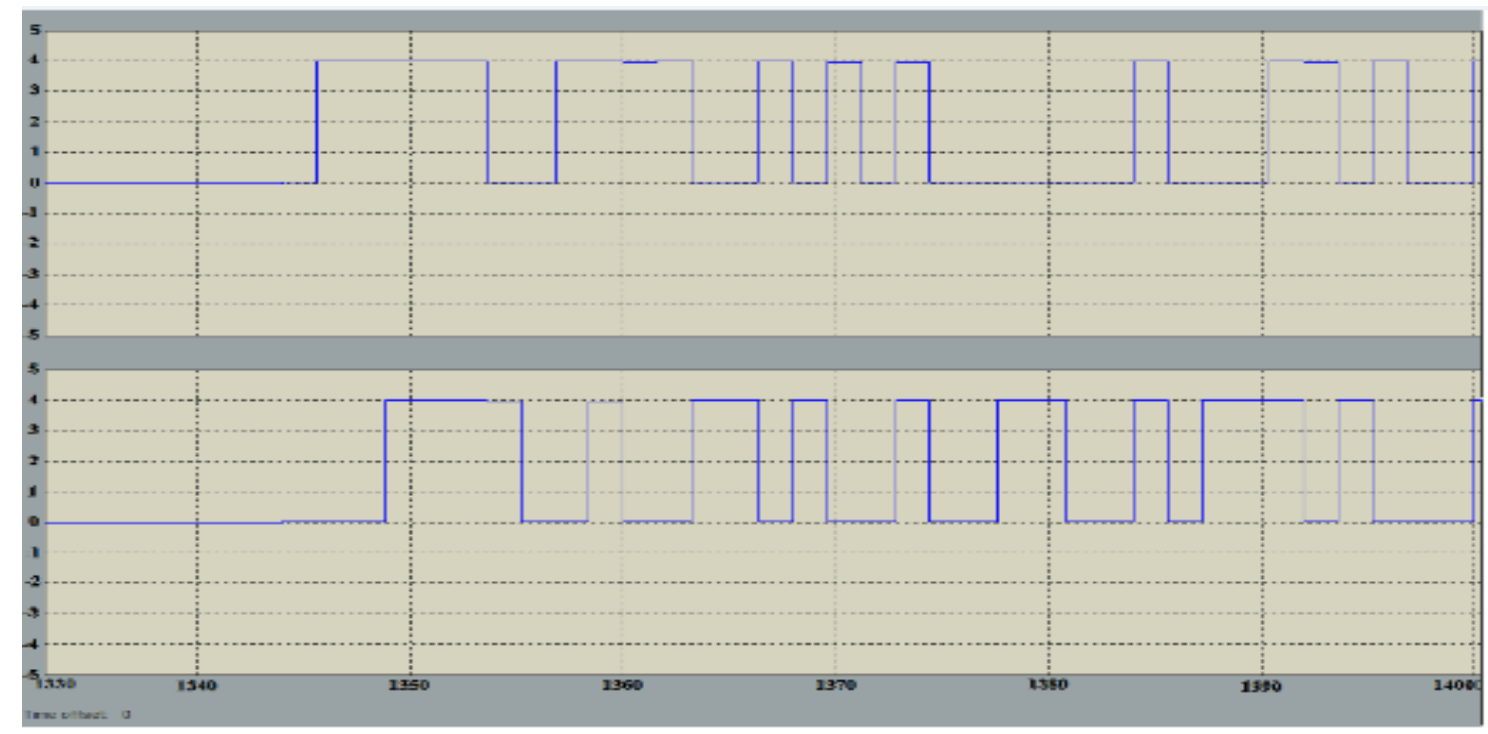

FIG.13. OUTPUT WAVEFORM FROM OFDM.

Fig. 14 describes the waveform of serial to parallel. The figures show the signal waveforms of the proposed designs of the serial to parallel based on XSG. These results of the Simulink are represented by the setup of serial to parallel.

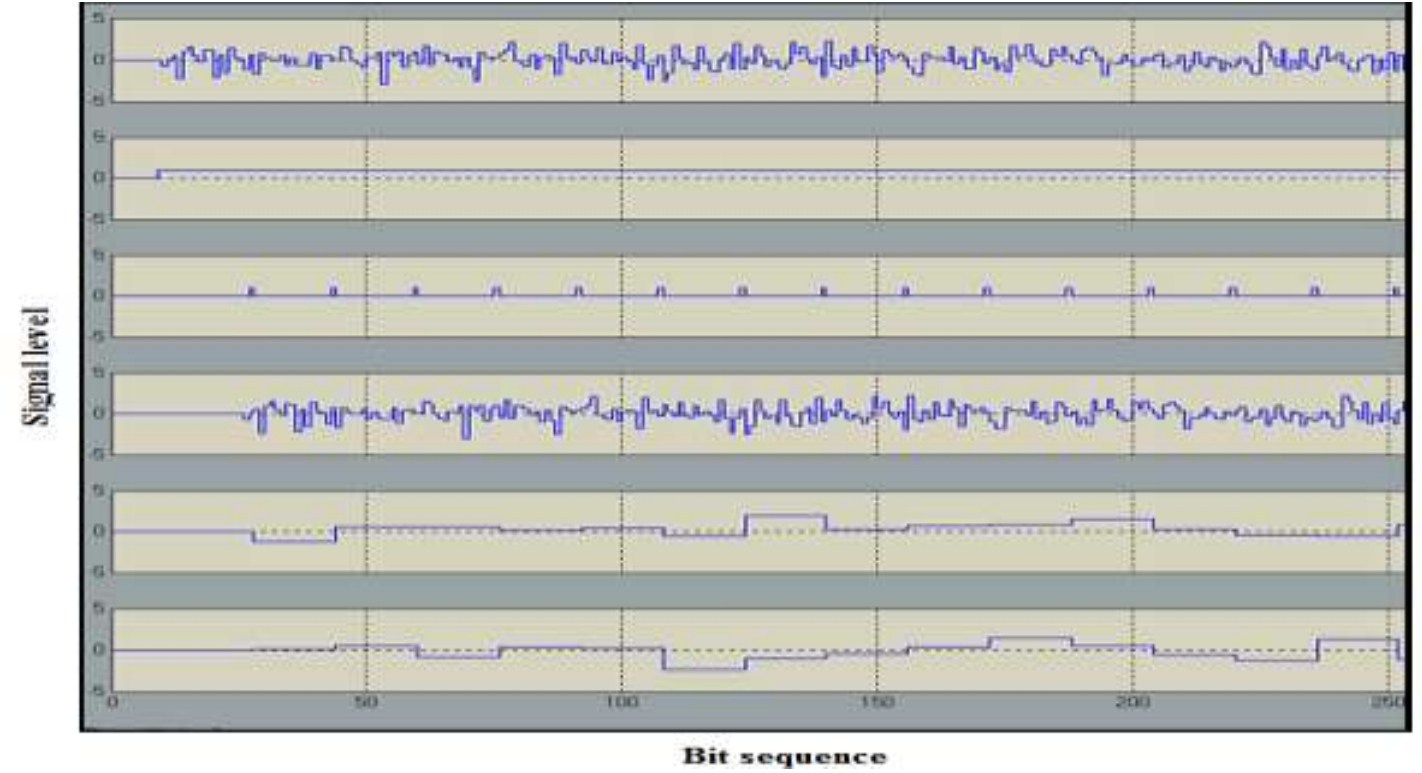

Fig.14. WAVEFORM OF SERIAL TO PARALLEL.

Finally, Fig. 15 represents the waveform of OFDM based on the energy detection.

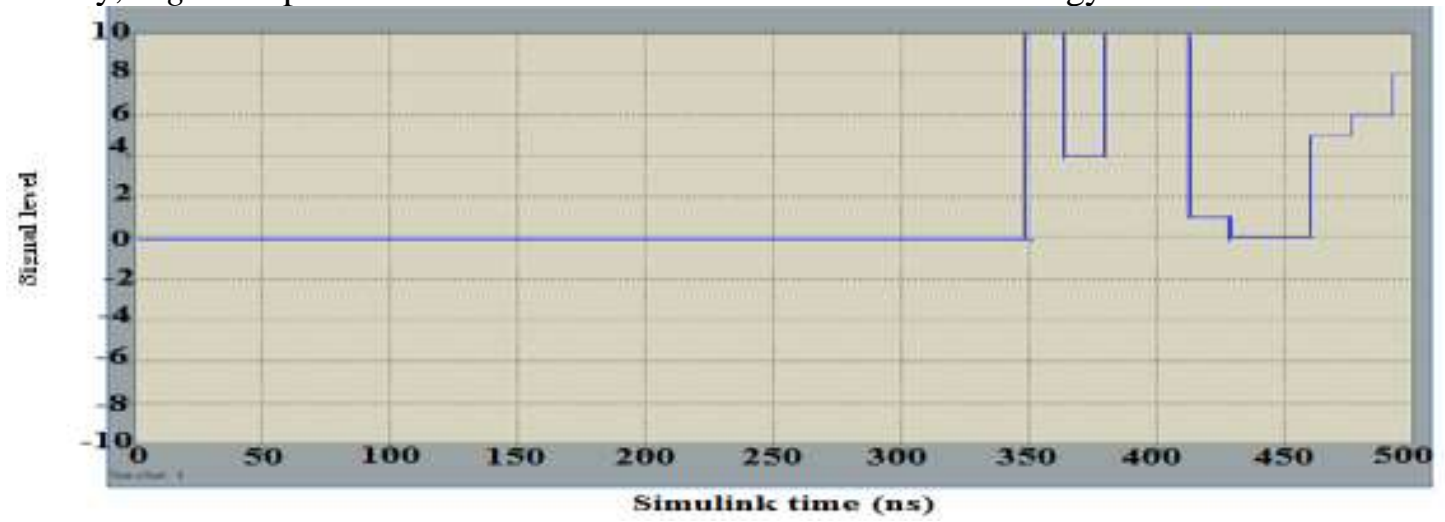

FIG.15. WAVEFORM OF OFDM BASED ON THE ENERGY DETECTION. 
DOI: https://doi.org/10.33103/uot.ijccce.21.2.5

TABLE 2. COMPARISION BETWEEN THE PRPOSED SYSTEM AND RELATED WORK.

\begin{tabular}{|c|c|c|}
\hline Authors (year) & $\begin{array}{c}\text { Software and Hardware } \\
\text { platform }\end{array}$ & Implementation Approach \\
\hline G.A. Pethunachiyar (2020) [1]. & Simulation using MATLAB. & $\begin{array}{l}\text { Analyzed the OFDM signal using QPSK } \\
\text { modulation, also it is integrated with energy } \\
\text { detection to detect the user. This explains } \\
\text { how the } 100 \text { percent accurate results for the } \\
\text { different sample sizes and low SNR values } \\
\text { are achieved. }\end{array}$ \\
\hline Fadhil, and Hasan (2017)[10]. & $\begin{array}{c}\text { Xilinx System Generator applied } \\
\text { on FPGA. }\end{array}$ & $\begin{array}{l}\text { Design the } 2 * 2 \text { Multiple-input, multiple- } \\
\text { output orthogonal frequency-division } \\
\text { multiplexing System using } 16 \text {-Quadrature } \\
\text { amplitude modulation modulation to solve } \\
\text { the ambiguity problem and implement FFT } \\
\text { in pipelining way. }\end{array}$ \\
\hline Bala, Diponkor (2020)[11]. & $\begin{array}{c}\text { All simulation is performed by } \\
\text { using MATLAB. }\end{array}$ & $\begin{array}{l}\text { Analyze the performance of OFDM using } \\
\text { different modulation (Binary phase-shift } \\
\text { keying, Quadrature Phase Shift Keying, 64- } \\
\text { Quadrature amplitude modulation, 128- } \\
\text { Quadrature amplitude modulation, 256- } \\
\text { Quadrature amplitude modulation). The } \\
\text { result concluded that with the presence of } \\
\text { BPSK modulation, the OFDM system } \\
\text { performed better performance compared to } \\
\text { the others. }\end{array}$ \\
\hline Proposed Model. & $\begin{array}{l}\text { All these stages will be build } \\
\text { MATLAB (2011a) simulation } \\
\text { and XILINX (ISE 1.14) system } \\
\text { generator. }\end{array}$ & $\begin{array}{l}\text { Analyze and design the OFDM transceiver } \\
\text { for Energy Detection of Cognitive Radio } \\
\text { based MATLAB/ Xilinx system generator. } \\
\text { Analyze the performance of the proposed } \\
\text { model consist of the OFDM transceiver } \\
\text { under the adaptive White Gaussian noise } \\
\text { (AWGN) channel for the cognitive radio } \\
\text { spectrum sensing algorithm with the energy } \\
\text { detector, using a MATLAB simulation. }\end{array}$ \\
\hline
\end{tabular}

\section{CONCLUSION}

From this work, several points that deal with the nature of cognitive adaptive radio systems can be inferred . It's very important to take care of the rapid developments in wireless communications, in particular, those related to the frequency spectrum and the availability of new bands to new users, which need to be taken care of. In this work, the use of the OFDM system based on Cognitive Radio energy detection improved the use of spectrum performance. OFDM transceiver-based energy detection system has been designed and simulated using Matlab/Simulink 2011a, and Xilinx system generator to demonstrate the possible performance under IEEE 802.22 Wireless regional area network standard. The OFDM transmitter has been designed using the QPSK modulation technique. For implementation, the energy-based detector spectrum sensing technique was chosen. The energy detector's algorithm performance was first tested using simulations with the Matlab method to construct a benchmark. 
DOI: https://doi.org/10.33103/uot.ijccee.21.2.5

\section{REFERENCES}

[1] G. A. Pethunachiyar, B.S., OFDM Based Energy Detection Algorithm for Spectrum Sensing in Cognitive Radio Networks. International Journal of Advanced Science and Technology, 2020. 29(3): p. 7296 - 7306.

[2] M., H Jia,. Yang, and X. Gu. Improved Energy Detection Spectrum Sensing Method for OFDM-Based Cognitive Radio System. in Communications, Signal Processing, and Systems. 2012. New York, NY: Springer New York.

[3] S.A Tahir,. and S. Ramavath. Volume-based spectrum sensing for OFDM based cognitive radio. in 2016 International Conference on Communication and Signal Processing (ICCSP). 2016.

[4] D. Sharma and P. Srivastava, OFDM Simulator using matlab. International Journal of Emerging Technology and Advanced Engineering, 2013. 3(9): p. 493-496.

[5] J., R. Singh Garg, and Aulakh I.K.. Effect of OFDM in cognitive radio: Advantages \& issues. in 2016 Second International Conference on Computational Intelligence \& Communication Technology (CICT). 2016. IEEE.

[6] Suliman, R.A.H., K.H. Bilal, and I. Elemam, Review paper on cognitive radio networks. Journal of Electrical \& Electronic Systems, 2018. 7(1): p. 1-3.

[7] M.Z., Alom, et al. Enhanced spectrum sensing based on energy detection in cognitive radio network using adaptive threshold. in 2017 International Conference on Networking, Systems and Security (NSysS). 2017. IEEE.

[8] M.T. Masonta, M. Mzyece, and N. Ntlatlapa, Spectrum decision in cognitive radio networks: A survey. IEEE Communications Surveys \& Tutorials, 2012. 15(3): p. 1088-1107.

[9] D., L. Hamza Mahdy, and A. Thabit, DESIGN AND IMPLEMENTATION OF COGNITIVE RADIO BASED ON XILINX FPGA. Journal of Engineering and Applied Sciences, 2019. 14: p. 892-897.

[10] S. Fadhil and F. Hasan, FPGA BASED 2×2 MMSE MIMO-OFDM SYSTEM USING XILINX SYSTEM GENERATOR. Journal of Engineering and sustainable development, 2017. 21: p. 152-177.

[11] D. Bala, Analysis the Performance of OFDM Using BPSK, QPSK, 64-QAM, 128-QAM \& 256-QAM Modulation Techniques. Journal of Electrical Engineering, Electronics, Control and Computer Science, 2020. 7(2): p. 31-38. 